\title{
Comparative study of Bayer-based imaging algorithms with student participation
}

\author{
Viktória Katica Vastag*, Tamás Óbermajer*, Attila Enyedi**, József Berke*** \\ * Informatics student, Dennis Gabor College, 1119 Budapest, Fejér Lipót street 70., \\ vastag.viktoria.k@gmail.com,flimaxo@gmail.com, \\ **IT Assistant, Dennis Gabor College, 1119 Budapest, Fejér Lipót street 70., enyedia@gdf.hu \\ *** College Professor, Dennis Gabor College, 1119 Budapest, Fejér Lipót street 70., berke@gdf.hu
}

\begin{abstract}
The Dennis Gabor College has a long-standing tradition where some tutors choose student demonstrators based on their knowledge and aptitude. For a student, the demonstrator's activity is an extra scope of duties. In such cases, they support their teacher's work, the instructors let them participate in the preparation of learning tutorials as well as encourage them to do scientific research work.
\end{abstract}

Every student is different. One of the most difficult parts of the teacher career is to find connection with the students and enjoy the work together. It is not only a studentteacher relationship but also a working relationship too.

It was nearly four years ago, when idea presented itself to examine interpolation algorithms based on different images and analyses. Initially, we took measurements on nine images. It was enough to prepare a BSc thesis in which hundreds of images had been evaluated by different methods. As the semesters passed there were new demonstrators and enthusiastic students who were interested in it. By now, there are four separate theses and several scientific research results and publications which are related to this topic.

Nowadays the most common sensors are the Bayer sensors which can be found in nearly all devices such as cameras, mobile phones, laptops, cars, etc. We need a sort of interpolation algorithm to process the RAW images in order to see them on our display as expected. The purpose of our measurements is to show both the students who attend digital image processing courses and both the researchers who are using images and working in the scientific field to how the elements of the images can affect the measurements.

We made our software to convert and cut the large TIFF files. The purpose of our software is to cut the large TIFF images without changing them. The popular market leaders are not able to save large TIFF images without lost or changed values after cutting. The software works on MAC OS and Win, too.

Based on our newest measurements, we demonstrate the accuracy of classifications which are based on Neural Network as well as how the imaging algorithms can affect the NDVI values. We compared nine different algorithms that have significant influence and we corroborate them with exact data and results.

In this publication, it will be explained how we can reach complex research results with the help of the students. We also demonstrate what are the benefits and pitfalls of educational work with complex methodological elements.

Keywords: image processing, education, demonstrator, student, research 


\section{INTRODUCTION}

It is an established tradition in higher education that teachers at universities/colleges pick talented students to help them. With the help of the instructors, a demonstrator is involved in his/her teacher's work which is related to the education or the research process. In the first semester, they only choose a student and give them smaller tasks to assess their eligibility. These tasks, for example, reading and understanding previous publications, visiting courses or conferences and getting to know about methodology of the researching. It is important to choose an independent, enthusiastic, creative and reliable person because it can be a more effective working relationship between the teacher and student, which is beneficial for both of them. A student knows his or her classmates better, so there will be a cohesive relationship between them to help each other during the semesters. Many students are afraid of asking their teachers about the curriculum, but if one of their classmates can give them direct help, then everyone can get the information faster and easier.

While demonstrators are doing their tasks, they can acquire interdisciplinary and deep knowledge about the specialized areas of the incredibly wide-ranging field of information technology. They can effectively acquire professional knowledge through practical tasks. It makes them more motivated and single-minded. They have more responsibility and extra work than the others, even though it adds a lot to their learning progress and future work.

Because of the demonstrator, a completely new world opens up to the instructor as well. They must learn how they can attract the audience's attention. Working with a demonstrator and training them is a serious and extra duty, but something it is also new and unusual. Everybody is different, everyone must be treated in different way. There are one or two students in the demonstrator position, so they can get much more attention from their instructor. At the beginning this is a masterdisciple relationship, but soon they become colleagues. Although there are several instructors who do not like treating a student as an equal colleague, but in our view, it is not disadvantageous, rather it can improve the work together. The authors of this publication are a demonstrator, graduate students, a young colleague and an instructor who are also the members of the research team.

\section{IMAGE PROCESSING IN THE EDUCATION}

During the education process, it is important to us that students cannot only participate in theoretical education, but also deepen their knowledge and experience with suitable practical and field tasks. With this approach, students gain high-quality practical experience in image processing, GIS (Geographic Information System), info-communication and remote sensing. During the field measurements, students have to perform simplified but real field tasks and they can also get experience in working and thinking in group [6]. Currently, there are several ongoing research projects around the Kis-Balaton involving our students.

With the spread of digital photography, besides the data transmission with the help of images, the processing of their meta-data has came into view. CCD and CMOS sensors can help in creating digital images. The chips are colorblind, therefore they are just detecting the intensity of light, though we can create color images with Bayer filter as well [1], [2]. The sensor makes raw images (RAW) which contain data directly from the sensor. This information also includes different wavelength ranges, but it depends on the type of the applied camera [6], [8].

The raw image is uninterpretable for the human eye, so we can use interpolation methods to create and visualize the information of the image. The data content of the images can be differ based on the various methods. 
Because of this, it is important to consider what we are measuring and which device we can use for the most accurate results. The aerial-based measurements require one of the most common information processing algorithms [5], [7], [11], [12], [14], [16].

The interpolation determines one or more values of unknow data, based on already known information [3], [4]. The differences between the algorithms come from mathematical methods and from the time of the implementation. Due to their different methods, you can divide them into two different groups: adaptive and non-adaptive.

- Nearest-neighbor

- Bilinear

- Smooth Hue Transition

- Smooth Hue Transition in logarithmic exposure space

- Edge Sensitive I.

- Edge Sensitive II.

- Linear Interpolation with Laplace Secondary Correction I. (Laplace I.)

- Linear Interpolation with Laplace Secondary Correction II. (Laplace II.)

- Threshold-based

In order to examine each algorithm, we have created a self-developed program package [15]. Part of this is the RAW / GreyScale TIFF image interpolation option. To extract the intensity data and convert the computed data into images - the open source LibRAW and LibTiff packages were used [17], [18]. The console programs were written in $\mathrm{C}++$ using Visual Studio [19], while the graphical interface was created using Qt community edition in Qt creator [20]. Due to platform independence, development has been implemented in Windows, Linux, and OS X systems.

In case of a digital image, we can determine the state of vegetation and development of vegetation by the help of Normalized Difference Vegetation Index (NDVI) rate. This is a rational number between $[-1, \ldots,+1]$ which is a useful indicator to examine the existence and developments of vegetation. NDVI value is the divided difference and sum of the reflected (radiometrically corrected) intensity of the vegetation in the near infrared (NIR) and visible red (RED) spectral range (1).

$$
N D V I=\frac{I_{N I R} I_{R E D}}{I_{N I R}+I_{R E D}}
$$

If this value is close to zero, it means the lack of vegetation or its disease. Around 0,2 to 0,3 means rear vegetation (for example grassland or brushy area) while 0.8 to 1.0 values indicate dense, green and healthy vegetation. The negative NDVI value does not presume vegetation (water, stone, rock, asphalt, roof, etc.) [9].

On average, digital cameras store have 12-16 bits information per channel. The applications which calculate the NDVI values are not prepared for this depth of intensity data. For this case we have created our software called NDVI16 which can measure 16-bit/channel TIFF images. The software uses a converted formula which uses the values of the threecolor channels instead of the near infrared and visible red values. The result is an integer between $[0, \ldots,+65536]$.

$$
\mathrm{NDVI}=\frac{(\text { Red }+ \text { Green })-(2 * \text { Blue })}{(\text { Red }+ \text { Green })+(2 * \text { Blue })}
$$

The value is always a ratio between 1 and -1 . It shows the presence of vegetation. This value requires further processing in order to get a scaled NDVI.

If the NDVI value is more than 0 , we use the following formula:

$$
\frac{N D V I}{0,15} \text {; if more than } 1 \text {, the result is } 1 \text {. }
$$

If the NDVI value is less than 0 , we use the following formula:

$$
\frac{N D V I}{-1 *(-0,3)} \text {; if less than }-1 \text {, the result is }-1 \text {. }
$$

After the calculations the software classifies the pixels into 20 classes based on the values. The classes are between $(-1, \ldots,+1)$ with decimal steps. Based on the grouping, it is 
possible to determine the proportion of healthy vegetation on an aerial image (Figure 1).

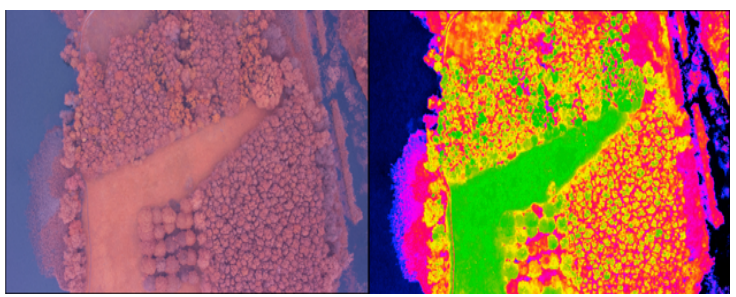

Figure 1. NDVI image before (left image) and after the processing (right image). Healthy vegetation is green, coherent water surface is black and other plants are yellow.

Our students learn about the NDVI calculations and their applications within Remote sensing, which is an optional subject that was announced in the last semester. In the previous semesters, we introduced them to other cameras which are not only recording in the visible range and also showed them the infrared, heat and NDVI images during the Digital Image Processing course in the 5th semester. The demonstrators' tasks are not simple because they know the information, the methods and the techniques before the planned curriculum. They have to be up to date with their own curriculum, but they also get further knowledge, which they can use in real research.

\section{MEASUREMENT RESULTS}

The examined area was the Zimányi Island which is part of the Kis-Balaton Landscape Protection Area (Figure 2).

There are varieties of plants which can be easily separated for classification. One of them is the Solidago gigantea invasive species which is not native to the island, but it also has significant influence on the native plants [10], [11], [13]. Figure 3 shows the NDVI classification results after the application of the nine algorithms measured in 16-bit images. The significant difference between the 20 classes for each algorithm is clearly visible [9].

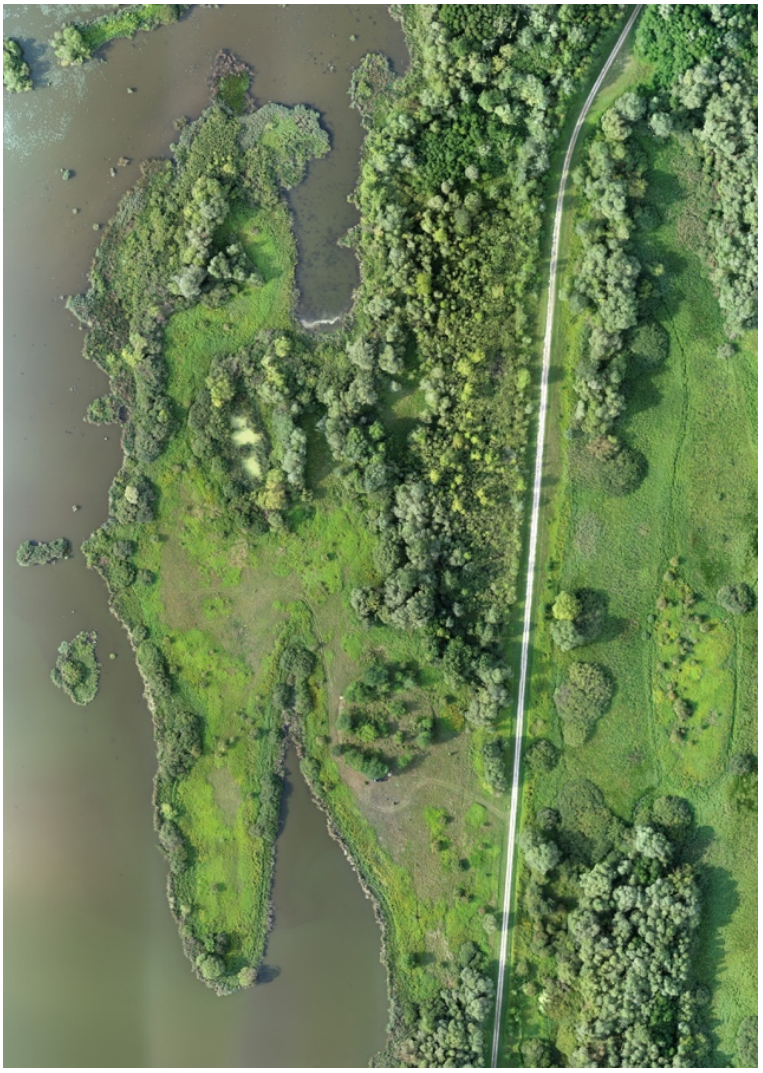

Figure 2. Aerial photography of our measurement area (Zimányi Island, 3 August 2018) in the visible (VIS) range

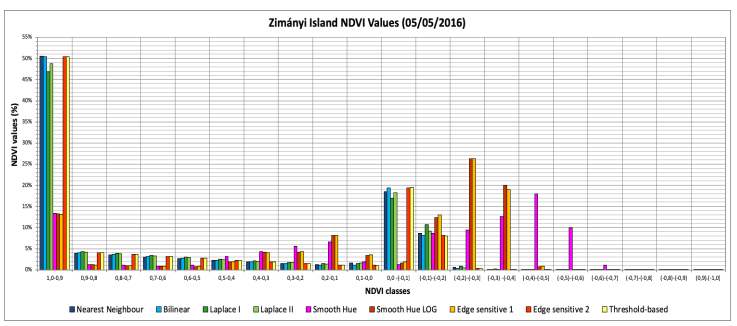

Figure 3. Change of the NDVI values (20 category) depending on the type of imaging algorithms

Figure 4 shows the three main categories (healthy vegetation, rare vegetation, inanimate objects).

- Within healthy vegetation (0.8-1.0), the difference between the individual algorithms was $40.2 \%$ (the lowest -Edge sensitive I.: $14.3 \%$, the highest -Thresholdbased: $54.5 \%$ ). 
- Within the rare vegetation category (0.0$0.3)$ the difference between the individual algorithms was $12.2 \%$ (the highest-Edge sensitive I.: $15.9 \%$, the lowest -Thresholdbased: $3.7 \%$ ).

- Within the inanimate objects category (0.0-1.0), the difference between the individual algorithms was $33.0 \%$ (the highest -Edge sensitive I.: $61.0 \%$, the lowest -Laplace II.: 28.0\%).

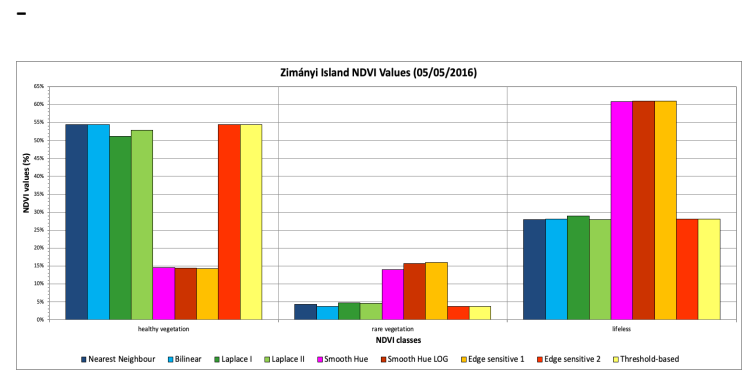

Figure 4. Change of the values of the three most significant NDVI categories (healthy vegetation, rare vegetation, inanimate objects) depending on the type of imaging algorithms

The previously presented Zimányi island was also examined by the Neural Network-based classification method. You can see the results on Figure 5.

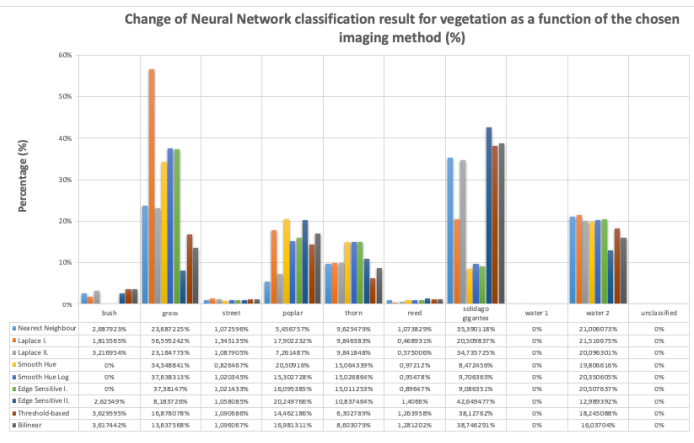

Figure 5. Effect of imaging algorithms on NN classification at the vegetation measurement

In the case of $\mathrm{NN}$, the solidago class is just the second largest class. Edge Sensitive II. algorithm has the highest result (42.65\% of the total picture, SVM has $32.49 \%$ ), while we got the lowest values with Smooth hue algorithm ( $8.47 \%$ of the total picture, $26.03 \%$ for SVM). We can clearly establish that in the case of NN, the deviation of the classification results between the algorithms continued to increase.

\section{OVERALL}

The many years, worth of experience shows that there are always some students who can be demonstrators. The teachers' choice is not easy because they look for a colleague for the time being and it is an enormous responsibility. Most students do not even know what the demonstrator's task/activity means, so they have enough time to think about their decision. It is always the result of the long learning process and performing smaller and larger tasks, as the current study shows. Within the Digital Image Processing, Remote Sensing, Geographic Information Systems and Infocommunication courses, students can acquire knowledge about the full process of aerial photography, practical knowledge and experience, in order to solve real problems later in their work. The extra tasks can help the demonstrators and students work on their thesis more easily. They can work in a team and do a report because they have done a lot of similar tasks during the semesters. As an experienced research teacher, I can declare that the invested work in preparing demonstrators is paying off, despite the fact that most graduate demonstrators do not stay in the educational field [21].

\section{REFERENCES}

[1] Bayer, B. E. 1976. „Color imaging array”, U.S. Patent 3,971,065.

[2] Bayer, B. E. 2015. Kodak scientist who created ubiquitous Bayer Filter for color digital imaging, has passed away. Online letöltés: 2015.12.10.

http://www.imagingresource.com/news/2012/11/20/brycebayer-who-created-bayer-filter-for-digitalcameras-has-died .

[3] Berke, D., Ocskai, Zs., Enyedi, A., Berke, J., 2015. Comparison of imaging methods for digital image sensors based on 
information content and image structure (hun). Fény-Tér-Kép konferencia. Gyöngyös, 2015. október 30.

[4] Berke, D., Ocskai, Zs., Major, K., Enyedi, A., Berke, J., 2016. Comparative analysis of digital imaging algorithms based on image structure and entropy (hun), VIII. Magyar Számítógépes Grafika és Geometria Konferencia, 2016. március 3031, Budapest, ISBN 978-615-5036-11-8.

[5] Berke, J., Enyedi, A., Berke, D., Ocskai, Zs., Major, K., 2016. Comparative analysis of high-resolution aerial imaging methods (hun), VII. Térinformatikai Konferencia és Szakkiállítás, Debrecen, 2016, 26/05/2016, pp. 83-90, ISBN 978-963-318-570-4, DOI: 10.13140/RG.2.1.4235.9923.

[6] Berke, J., Kelemen, D., Kozma-Bognár, V., Magyar, M., Nagy, T., Szabó, J., Temesi, T., 2010. Digital image processing and their applications (DIGKEP v7.0). Electronic and printed textbook (hun). Kvark Számítástechnikai Bt., Keszthely. ISBN 978-963-06-7825-4.

[7] Enyedi A. 2016. Comparison of Bayertype imaging techniques based on information content and image structure, Thesis, Gábor Dénes Föiskola, Mérnökinformatikus szak. Budapest.

[8] Enyedi, A., Kozma-Bognár, V., Berke, J. 2016. Comparison of remote sensing imaging algorithms based on content and structure (hun), Remote Sensing Technologies \& GIS Journal, 2016:6(6), pp. 464-475., ISSN: 2062-8617.

[9] Berke, J., Báldoghi, T., Major, K., KozmaBognár V. (2017): Impact of Imaging Algorithms on NDVI Index (hun), VIII. Térinformatikai Konferencia és Szakkiállítás, Debrecen, 2017. május 2526., pp. 51-56., ISBN: 978-963-318-638-1.

[10] Berke, J., Kozma-Bognár V., Ocskai, Zs., Enyedi, A. (2017): Comparison of Bayerbased imaging algorithms based on information content and image structure (hun), Képfeldolgozók és Alakfelismerők Társaságának 11. Országos konferenciája, Szováta, Erdély, Románia, 2017. Január 24-27, pp. 1-16.

[11] Magyary, V., 2016. Fit and classify ultrahigh resolution aerial images (hun). Thesis.
Gábor Dénes Főiskola Mérnökinformatikus szak, Budapest.

[12] Major, K. 2017. Examination of the effect of imaging algorithms on classification methods (hun), Thesis. Gábor Dénes Főiskola, Mérnökinformatikus szak. Budapest.

[13] Major, K., Kozma-Bognár, V., Enyedi, A., Váradi, Á., Berke, J. 2016. Applying remote-controlled drones for research purposes in education (hun), XXII. „Multimédia az Oktatásban” nemzetközi konferencia, Keszthely, pp. 22-27., ISBN 978-615-80204-3- 5, DOI: 10.13140/RG.2.1.1361.1122

[14] Ocskai, Zs., 2015. Entropy-based information content measurement on digital images (hun). Thesis. Gábor Dénes Főiskola, Mérnökinformatikus szak. Budapest.

[15] qChannel, 2018. Online download: 2018.05.13.

http://www.req.hu/kepfeldolgozas/qchanne $1 /$.

[16] Szilágyi, J. 2013. Vegetation classification of multispectral images by ENVI SVM classification procedure (hun), Thesis. Gábor Dénes Főiskola, Mérnökinformatikus szak. Budapest.

[17] LibRAW develope site: http://www.libraw.org.

[18] LibTiff develope site: http://www.simplesystems.org/libtiff .

[19] Official site of Visual Studio https://www.visualstudio.com.

[20] Official site of Qt platform https://www.qt.io.

[21] Vastag, V. K., 2018. Evaluation of Solidago gigantea invasive species in image processing based on hypertemporal drone images (hun), Thesis. Gábor Dénes Főiskola, Mérnökinformatikus szak. Budapest. 